\title{
DIGITALCOMMONS
}

$11-2014$

\section{Pairwise Comparison in Repeated Measures}

I.C.A. Oyeka

Nnamdi Azikiwe University, Awka, Nigeria, cyprainoyeka@yahoo.com

C. C. Nnanatu

Nnamdi Azikiwe University, Awka, Nigeria, nnanatuchibuzor@yahoo.com

Follow this and additional works at: http://digitalcommons.wayne.edu/jmasm

Part of the Applied Statistics Commons, Social and Behavioral Sciences Commons, and the Statistical Theory Commons

\section{Recommended Citation}

Oyeka, I.C.A. and Nnanatu, C. C. (2014) "Pairwise Comparison in Repeated Measures," Journal of Modern Applied Statistical Methods: Vol. 13 : Iss. 2 , Article 8.

DOI: $10.22237 /$ jmasm/1414814820

Available at: http://digitalcommons.wayne.edu/jmasm/vol13/iss2/8

This Regular Article is brought to you for free and open access by the Open Access Journals at DigitalCommons@WayneState. It has been accepted for inclusion in Journal of Modern Applied Statistical Methods by an authorized editor of DigitalCommons@WayneState. 


\section{Pairwise Comparison in Repeated Measures}

\author{
I. C. A. Oyeka \\ Nnamdi Azikiwe University \\ Awka, Nigeria
}

\author{
C. C. Nnanatu \\ Nnamdi Azikiwe University \\ Awka, Nigeria
}

Sometimes a random sample of subjects or patients may be exposed to a battery of diagnostic tests or medication over time and interest is on determining whether there is progressive remission of condition, disease or symptom. Also perhaps early in a program or experiment, subjects or candidates may be required to significantly improve in their performance rates at the current trial relative to an immediately preceding trial, otherwise they may have to withdraw from or drop out. The research interest would then be to determine some critical minimum marginal success rate to guide the management in decision making as well as in policy implementation. Success rates lower than the minimum expected value would indicate a need for some remedial actions. A method of estimating these rates is proposed assuming that the requirement is at the second trial. Pairwise comparisons of proportions of success or failure by subjects or candidates in a sequence of experiments or trials over time or space are conducted to ascertain which subject or combinations is responsible for the rejection of the null hypothesis. The proposed methods is illustrated and shown to be at least as efficient and powerful as competitors.

Keywords: $\quad$ Repeated measures, data coding, pairwise comparison

\section{Introduction}

Sometimes a researcher may obtain repeated measurements or responses on objects, subjects or items, often measured on an ordinal scale over space or over a number of time periods or set of treatment conditions, experiments or trials. The subjects or candidates are considered random but the treatment conditions may be either fixed or also random. These data may not be available in numerical form, but in the form of letter grades earned by candidates at examinations, continuous assessments or job interviews, grades (or grade point averages) earned at the end of each year during students' studies in an educational institution, etc. Thus each subject or candidate is exposed to each of the experimental conditions over time or space.

I.C.A. Oyeka is a professor of statistics in the Department of Statistics at Nnamdi Azikiwe University; Email him at cyprainoyeka@yahoo.com. C.C. Nnanatu is a statistics lecturer at Nnamdi Azikiwe University. Email himatnnanatuchibuzor@yahoo.com. 


\section{PAIRWISE COMPARISON IN REPEATED MEASURES}

At each of these instances, the interest may be in determining whether the subjects improved their performances or chances of success over the set of treatment conditions during the study or experimental period. That is, interest is in testing whether the proportions of positive responses are the same or different over a set of treatment conditions.

If the null hypothesis of no improvement is rejected in which case, there perhaps exists some improvements in performance or increases in proportions of positive responses, one may then proceed further to statistically examine any observed patterns in these increases, with a view to ascertaining which of the treatment conditions or their combinations may have led to a rejection of the null hypothesis of equal experimental conditions or treatment proportions of success. Often interest in these regards may be in determining whether the subjects on the average successively improve their performance rather than in multiple comparisons of all the treatment conditions. That is, research interest may be in pairwise comparisons of proportions of success or failure by subjects or candidates in a sequence of experiments or trials over time or space.

Several nonparametric methods exist for answering these questions. For example one may rank order the observations for each subject or candidate across the treatment conditions and then apply any of the non-parametric methods used in analyzing ordered data (see for example Conover, 1980; Friedman, 1937; Oyeka, 1986; Page, 1963; Prentice, 1978; Puri and Sen, 1967; Kempthorne, 1979).

\section{The Proposed Method}

A method is proposed based on an earlier work by Oyeka (1990). Assume that there are $r$ independently drawn subjects candidates involved in the study each of whom is observed and scored at each of time periods, location or treatment conditions.

Specifically let $x_{i j}$ be the score or grade earned by the $i^{\text {th }}$ subject at the $j^{\text {th }}$ treatment condition or trial for $i=1,2, \ldots, r$ and $j=1,2, \ldots, c$. The data format is as in Table 1.

Now let

$$
u_{i j}=\left\{\begin{array}{l}
1, \text { if } x_{i j}>x_{i, j-1} \\
0, \text { otherwise }
\end{array}\right.
$$

For $i=1,2, \ldots, r$ and $j=2,3, \ldots, c$

Thus the $i^{\text {th }}$ subject or candidate is assigned a score of 1 if the subject's score or grade of the current trial, interview, examination, experiment or location is 


\section{OYEKA \& NNANATU}

higher than the subject score of the immediately preceding trial; otherwise the candidate is assigned a score of 0 .

Table 1. Data format for the scores or grades earned by the $f^{\text {th }}$ subject at the $j^{\text {th }}$ treatment condition.

\begin{tabular}{c|ccccc} 
& \multicolumn{5}{c}{ Treatment } \\
\cline { 2 - 6 } Subject & $\mathbf{1}$ & $\mathbf{2}$ & $\mathbf{3}$ & $\ldots$ & $\boldsymbol{c}$ \\
\hline $\mathbf{1}$ & $x_{11}$ & $x_{12}$ & $x_{13}$ & $\ldots$ & $x_{1 c}$ \\
$\mathbf{2}$ & $x_{21}$ & $x_{22}$ & $x_{23}$ & $\ldots$ & $x_{2 c}$ \\
$\mathbf{3}$ & $x_{31}$ & $x_{32}$ & $x_{33}$ & $\ldots$ & $x_{3 c}$ \\
$\vdots$ & $\vdots$ & $\vdots$ & $\vdots$ & & $\vdots$ \\
$\boldsymbol{r}$ & $x_{r 1}$ & $x_{12}$ & $x_{13}$ & $\ldots$ & $x_{r c}$ \\
\hline
\end{tabular}

This coding scheme is also appropriate if interest is in comparing one treatment, location or period (control) with the others. In this case an observation in any of the other treatments is coded if it is greater than the corresponding observation in the control treatment, otherwise it is coded 0 .

Let

$$
\pi_{j}=p\left(u_{j}=1\right)
$$

and

$$
t_{j}=\sum_{i=1}^{r} u_{i j}
$$

Note that $t_{j}$ is the number of ones ( 1 's) or successes by subjects in the current trial relative to the immediately preceding trial. The corresponding number of zeroes ( 0 's) or failures is $r-t_{j}$. Let

$$
n_{1 .}=t=\sum_{j=2}^{c} t_{j}
$$

be the total number of 1 's for all the $c$ experimental conditions and let

$$
n_{2 .}=\sum_{j=2}^{c} r-t_{j}=r(c-1)-t
$$




\section{PAIRWISE COMPARISON IN REPEATED MEASURES}

be the total number of 0 's or failures for all the $c$ treatment conditions.

Hence,

$$
E\left[u_{i j}\right]=\pi_{j} ; \operatorname{Var}\left(u_{i j}\right)=\pi_{j}\left(1-\pi_{j}\right)
$$

and

$$
E\left[t_{j}\right]=r \pi_{j} ; \operatorname{Var}\left(t_{j}\right)=r \pi_{j}\left(1-\pi_{j}\right)
$$

Note that $\pi_{j}$ is the proportion of 1 's or successes in the current $j^{\text {th }}$ trial relative to the immediately preceding $(j-1)^{\text {th }}$ trial and is estimated as

$$
p_{j}=\frac{t_{j}}{r}
$$

and the corresponding variance is estimated as

$$
\operatorname{Var}\left(p_{j}\right)=\frac{\hat{\pi}_{j}\left(1-\hat{\pi}_{j}\right)}{r}=\frac{t_{j}\left(r-t_{j}\right)}{r^{3}}
$$

If the proportions of successes are the same for all the $c$ trials or treatments then the common proportion may be estimated as

$$
p=\frac{t}{r(c-1)}
$$

These results may be summarized in a $2 \times(c-1)$ table, as in Table 2 .

The observed number of 1's or successes and number of 0 's or failures for the

$j^{\text {th }}$ treatment condition are respectively

$$
O_{1 j}=t_{j} \text { and } O_{2 j}=r-t_{j}
$$




\section{OYEKA \& NNANATU}

Table 2. $2 \times(c-1)$ Table for Analysis for Repeated Measures.

\begin{tabular}{lccccc} 
& \multicolumn{5}{c}{ Treatment Conditions } \\
\cline { 2 - 6 } Observations & $\mathbf{2}$ & $\mathbf{3}$ & $\ldots$ & $\mathbf{c}$ & Total \\
\hline Number of 1's $\left(\boldsymbol{t}_{j}\right)$ & $t_{2}$ & $t_{3}$ & $\ldots$ & $t_{c}$ & $t$ \\
Number of 0's $\left(r-\boldsymbol{t}_{j}\right)$ & $r-t_{2}$ & $r-t_{3}$ & $\ldots$ & $r-t_{c}$ & $r(c-1)-t$ \\
Total & $r$ & $r$ & $\ldots$ & $r$ & $r(c-1)$ \\
Proportion $\left(\boldsymbol{p}_{\boldsymbol{j}}\right)$ & $p_{2}$ & $p_{3}$ & $\ldots$ & $p_{c}$ & $p=\frac{t}{r(c-1)}$ \\
\hline
\end{tabular}

Under the Null hypothesis of equal population proportions of successes for all the treatment or experimental conditions, the corresponding expected numbers of 1 's (successes) and 0's (failures) are respectively

$$
E_{1 j}=\frac{r t}{r(c-1)} \text { and } E_{2 j}=\frac{r(r(c-1)-t)}{r(c-1)}
$$

and under the null hypothesis of no difference between treatments or periods in the success rates achieved, the test statistic

$$
\chi^{2}=\sum_{i=1}^{2} \sum_{j=2}^{c} \frac{\left(O_{i j}-E_{i j}\right)^{2}}{E_{i j}}
$$

has approximately a chi-square distribution with $c-1$ degrees of freedom and may be used to test the null hypothesis of no difference in success rates.

Now using Equations (11) and (12)

$$
\chi^{2}=\sum_{j=2}^{c}\left(\frac{\frac{\left(t_{j}-r t\right)^{2}}{r(c-1)}}{\frac{r t}{r(c-1)}}\right)+\sum_{j=2}^{c}\left(r-t_{j}\right)-\frac{\frac{r(r(c-1)-t)^{2}}{r(c-1)}}{\frac{r(r(c-1)-t)}{r(c-1)}}
$$

which when simplified yields 


\section{PAIRWISE COMPARISON IN REPEATED MEASURES}

$$
\chi^{2}=\frac{r(c-1)^{2}}{t(r(c-1)-t)} \sum_{j=2}^{c} \frac{\left(t_{j}-t\right)^{2}}{(c-1)}
$$

which has approximately a chi-square distribution with $c-1$ degrees of freedom.

An equivalent expression for Equation (13) in terms of the proportions in Equations (8) and (10) is

$$
\chi^{2}=\frac{r \sum_{j=2}^{c}\left(p_{j}-p\right)^{2}}{p q}
$$

and may be used to test the null hypotheses of equal population proportion success provided $r c \geq 30$, where $q=1-p$.

The null hypothesis, $H_{0}$ is rejected at the $\alpha$ level of significance if

$$
\chi^{2} \geq \chi_{1-\alpha ; c-1}^{2}
$$

otherwise $H_{0}$ is accepted.

If $H_{0}$ is rejected then one may wish to proceed to investigate further which treatments, experimental conditions or their combinations may have led to the rejection of the null hypothesis. In particular, one may wish to test whether subjects are successively improving their performance over time, space or experimental conditions.

Now let $\pi_{j}$ and $\pi_{k}$ as defined above be the population proportions of positive responses or successes at the $j^{\text {th }}$ and $k^{\text {th }}$ trials respectively for $j, k=2,3, \ldots, c, j \neq k$, with the corresponding sample estimates of $p_{j}$ and $p_{k}$ respectively.

$$
p_{j}=\frac{t_{j}}{r} \text { and } p_{k}=\frac{t_{k}}{r} \text { as in equation (8). }
$$

Note that $\pi_{j}$ and $\pi_{k}$ respectively measure the percentage increases in performance by a population of subjects at the $j^{\text {th }}$ and $k^{\text {th }}$ treatment conditions relative to their performance at the $(j-1)^{\text {th }}$ and $(k-1)^{\text {th }}$ treatment conditions respectively. Interest may then be in testing either the null hypothesis that these relative improvement rates differ by some constants or the null hypothesis that each of the relative difference equal to some constant or the null hypothesis that there is 


\section{OYEKA \& NNANATU}

no relative improvement. Notationally, these null hypotheses may be expressed as either

1. $H_{o}: \pi_{j}-\pi_{k} \geq \pi_{0}$ versus $H_{1}: \pi_{j}-\pi_{k}<\pi_{0}$, say, $j \neq k,\left(-1<\pi_{0}<1\right)$

2. $H_{o}: \pi_{j}-\pi_{0}$ versus $H_{1}: \pi_{j}<\pi_{0}$, say $j=2,3, \ldots, c$

To test the null hypothesis of equation (18), note that the sample estimate of $\pi_{j}-\pi_{k}$ is $p_{j}-p_{k}$. Let

$$
z=\frac{\left(p_{j}-p_{k}\right)-\pi_{o}}{s_{e}\left(p_{j}-p_{k}\right)}
$$

where $s_{e}\left(p_{j}-p_{k}\right)$ is the standard deviation of $p_{j}-p_{k}$ given as

$$
s_{e}\left(p_{j}-p_{k}\right)=\sqrt{\operatorname{Var}\left(p_{j}\right)+\operatorname{Var}\left(p_{k}\right)-2 \operatorname{Cov}\left(p_{j}, p_{k}\right)}
$$

where

$$
\begin{aligned}
\operatorname{Cov}\left(p_{j}, p_{k}\right)= & E\left[p_{j} p_{k}\right]-E\left[p_{j}\right] E\left[p_{k}\right] \\
& =\frac{E\left[t_{j} t_{k}\right]}{r^{2}}-\frac{E\left[t_{j}\right] E\left[t_{k}\right]}{r}, \text { see equation (8) } \\
& =\frac{\sum_{i=1}^{r} \sum_{s=1}^{r} E\left[u_{i j} u_{s k}\right]}{r^{2}}-\pi_{j} \pi_{k}, \text { see equation (7) }
\end{aligned}
$$

Now $u_{i j} \cdot u_{s k}$ assumes the value 1 if and only if $u_{i j}$ and $u_{s k}$ both assume the value 1 with probability $\pi_{j} \pi_{k}$.

Therefore,

$$
\frac{\sum_{i=1}^{r} \sum_{s=1}^{r} E\left[u_{i j} u_{s k}\right]}{r^{2}}=\frac{r^{2}\left(\pi_{j} \pi_{k}\right)}{r^{2}}=\pi_{j} \pi_{k}
$$




\section{PAIRWISE COMPARISON IN REPEATED MEASURES}

Hence,

$$
\operatorname{Cov}\left(p_{j}, p_{k}\right)=\pi_{j} \pi_{k}-\pi_{j} \pi_{k}=0
$$

Therefore,

$$
\operatorname{Var}\left(p_{j}-p_{k}\right)=\operatorname{Var}\left(p_{j}\right)+\operatorname{Var}\left(p_{k}\right)
$$

Under the null hypothesis of (18) the statistic $z$ of (20)

$$
z=\frac{\left(p_{j}-p_{k}\right)}{s_{e}\left(p_{j}-p_{k}\right)}-\pi_{o}=\frac{\left(p_{j}-p_{k}\right)-\pi_{o}}{\sqrt{\operatorname{Var}\left(p_{j}\right)+\operatorname{Var}\left(p_{k}\right)}}
$$

which is the unit normal distribution. Hence,

$$
\chi^{2}=z^{2}=\frac{\left(\left(p_{j}-p_{k}\right)-\pi_{o}\right)^{2}}{\operatorname{Var}\left(p_{j}\right)+\operatorname{Var}\left(p_{k}\right)}
$$

has approximately a chi-square distribution with 1 degree of freedom where $p_{j}$ is given in (8) and

$$
\operatorname{Var}\left(p_{j}\right)=\frac{t_{j}\left(r-t_{j}\right)}{r^{3}}, \text { see equation (9). }
$$

Under the null hypothesis of no difference between the population or treatment proportions of success and overall estimate of $\pi_{j}$ namely $p_{j}$ is $p$ given in (10). Hence the variance of $p_{j}$ may be estimated as

$$
\operatorname{Var}\left(p_{j}\right)=\frac{p(1-p)}{r}=\frac{t(r(c-1)-t)}{r^{3}(c-1)^{2}}
$$




\section{OYEKA \& NNANATU}

Therefore, the test statistic for testing the null hypothesis, $H_{0}$ of Equation (18), is given in Equation (24) as:

$$
\chi^{2}=z^{2}=\frac{\left(\left(\frac{t_{j}}{r}-\frac{t_{k}}{r}\right)-\pi_{o}\right)^{2}}{\operatorname{Var}\left(p_{j}\right)+\operatorname{Var}\left(p_{k}\right)}=\frac{\left(\left(\frac{t_{j}}{r}-\frac{t_{k}}{r}\right)-\pi_{o}\right)^{2}}{2 \operatorname{Var}(p)}
$$

where under $H_{0}$,

$$
\begin{aligned}
\operatorname{Var}\left(p_{j}\right) & =\operatorname{Var}\left(p_{k}\right)=\operatorname{Var}(p) \\
& =\frac{t(r(c-1)-t)}{r^{3}(c-1)^{2}}, \text { see equation (23) }
\end{aligned}
$$

The test statistics of (22) may be expressed as

$$
\chi^{2}=\frac{r^{3}(c-1)^{2}\left(\frac{t_{j}}{r}-\frac{t_{k}}{r}\right)}{t(r(c-1)-t)}-\pi_{o}
$$

or equivalently in terms of the proportions in (8) and (10)

$$
\chi^{2}=\frac{r\left(\left(p_{j}-p_{k}\right)-\pi_{o}\right)^{2}}{2 p(1-p)}
$$

which has approximately a chi-square distribution with 1 degree of freedom.

The test statistics of equation (26) may be used to test the null hypothesis that the proportion of positive responses or successes in the $j^{\text {th }}$ treatment condition is higher than the corresponding proportion in the $k^{\text {th }}$ treatment condition by at least some value, $\pi_{o}$. The statistics of equation (26) may be compared with an appropriately chosen critical value of the chi-squared distribution with degrees of freedom at a specified significance level $\alpha$. However to keep the type 1 error small and control for erroneous conclusions, it is suggested that all comparisons be made against critical chi-square values with $c-1$ degrees of freedom at a specified $\alpha$ level. 


\section{PAIRWISE COMPARISON IN REPEATED MEASURES}

To test the null hypothesis of equation (19), that is that the positive response or success rate at the $j^{\text {th }}$ experimental or treatment condition is greater than the corresponding success rate at the $(j-1)^{\text {th }}$ experimental condition by at least some constant $\pi_{o}$, we use the test statistics

$$
\chi^{2}=\frac{\left(p_{j}-\pi_{o}\right)^{2}}{\operatorname{Var}\left(p_{j}\right)}
$$

Under $H_{o}$ this becomes

$$
\chi^{2}=\frac{\left(p_{j}-\pi_{o}\right)^{2}}{\operatorname{Var}\left(p_{j}\right)}=\frac{r^{3}(c-1)^{2}\left(\frac{t_{j}}{r}-\pi_{o}\right)^{2}}{t(r(c-1)-t)}=\frac{r\left(p-\pi_{o}\right)^{2}}{p(1-p)}
$$

which has approximately a chi-square distribution with 1 degree of freedom. The test statistics of equation (27) may therefore similarly be used to test the null hypothesis that the proportion of positive responses or successes in the current, that is in the $j^{\text {th }}$ treatment condition is at least equal to the corresponding proportion of positive responses in the immediately preceding, that is in the $(j-1)^{\text {th }}$ treatment on experimental condition, although as suggested earlier all comparisons should preferably be made against critical chi-square values with $c-1$ degrees of freedom.

If subjects or candidates are required to significantly improve their success rates early in the study or experiment, for example, at the second trial so that the success rate at the second trial is expected to be significantly greater than the success rate in the first trial then the null hypothesis of no difference between the success rates in these two trials must be rejected. This implies that for a given value of $r$ and specified $\alpha$ level, the test statistics of equation (27) must be such that

$$
\chi^{2}=\frac{r^{3}\left(\frac{t_{2}}{r}-0\right)^{2}}{t_{2}\left(r-t_{2}\right)} \geq \chi_{1-\alpha ; 1}^{2}
$$


and thus

$$
\frac{p_{2}}{1-p_{2}} \geq \frac{\chi_{1-\alpha ; 1}^{2}}{r}
$$

(28) is an estimate of the odds that a randomly selected candidate or subject performs significantly better in the second than in the first trial. In other words for a given number of subjects $r$ and specified significance level $\alpha$, the estimated probability $p_{2}$ that a randomly selected subject for some experiment or study, performs significantly better or significantly improves his performance at the second trial relative to the first trial must be such that

$$
p_{2} \geq \frac{\chi_{1-\alpha ; 1}^{2}}{r+\chi_{1-\alpha ; 1}^{2}}
$$

\section{Illustrative Examples}

\section{Example 1}

If $r=20$ and $\alpha=0.05$ or 0.01 , then

$$
p_{2} \geq \frac{3.841}{23.841}=0.161, \text { or } p_{2} \geq \frac{5.991}{25.991}=0.23
$$

Under these circumstances a randomly selected subject or candidate in the program of interest would have to earn at least 16.1 percent or 23.0 percent higher in the current or second trial relative to the immediately preceding or first trial to be able to continue with the experiment or program.

\section{Example 2}

Shown in Table 3 are the grade-point-averages (GPAs) earned in each of the five years a random sample of 23 students who studied medical statistics at a certain university. 


\section{PAIRWISE COMPARISON IN REPEATED MEASURES}

Table 3. Grade Point Averages (GPA) of a Random Sample of Students

\begin{tabular}{lccccc} 
Student & Year I & Year 2 & $\begin{array}{c}\text { Year of Study } \\
\text { Year 3 }\end{array}$ & Year 4 & Year 5 \\
\hline 1 & 2.06 & 2.05 & 2.29 & 2.67 & 1.00 \\
2 & 1.38 & 2.08 & 2.42 & 2.76 & 1.00 \\
3 & 3.54 & 3.71 & 3.88 & 3.57 & 5.00 \\
4 & 1.33 & 2.17 & 2.33 & 1.86 & 2.22 \\
5 & 2.02 & 2.37 & 2.29 & 2.60 & 1.00 \\
6 & 3.08 & 3.30 & 3.36 & 3.73 & 1.00 \\
7 & 1.21 & 2.30 & 2.70 & 2.00 & 2.44 \\
8 & 1.35 & 2.25 & 2.06 & 2.00 & 2.44 \\
9 & 1.88 & 1.82 & 3.64 & 3.39 & 2.00 \\
10 & 2.06 & 3.14 & 2.44 & 3.00 & 1.00 \\
11 & 1.85 & 2.50 & 2.51 & 2.80 & 1.00 \\
12 & 1.94 & 1.39 & 1.83 & 1.06 & 1.00 \\
13 & 2.91 & 3.39 & 2.91 & 2.13 & 4.00 \\
14 & 4.16 & 2.17 & 1.57 & 1.21 & 1.25 \\
15 & 1.50 & 1.90 & 1.50 & 1.79 & 3.50 \\
16 & 1.54 & 2.85 & 2.73 & 1.00 & 1.50 \\
17 & 1.96 & 2.21 & 2.57 & 2.00 & 1.00 \\
18 & 1.24 & 2.29 & 1.04 & 1.74 & 2.00 \\
19 & 1.26 & 2.67 & 1.20 & 1.18 & 1.50 \\
20 & 1.49 & 2.21 & 2.57 & 1.71 & 1.00 \\
21 & 1.55 & 2.50 & 1.86 & 1.21 & 2.00 \\
22 & 2.46 & 2.39 & 3.56 & 3.50 & 1.00 \\
23 & 1.33 & 2.16 & 1.25 & 2.12 & 1.43 \\
\hline & & & & &
\end{tabular}

The research interest is to determine whether or not students in the program progressively improved their academic performance. To answer this question apply (1) with the data of Table 2 to generate the corresponding coded data of 1's and 0's shown in Table 4. 


\section{OYEKA \& NNANATU}

Table 4. Patterns of 1's and 0's for Data in Table 3.

\begin{tabular}{|c|c|c|c|c|c|}
\hline \multirow[b]{2}{*}{ Student } & \multicolumn{5}{|c|}{ Year of study } \\
\hline & Year 2 & Year 3 & Year 4 & Year 5 & Total \\
\hline 1 & 0 & 1 & 1 & 0 & -- \\
\hline 2 & 1 & 1 & 1 & 0 & -- \\
\hline 3 & 1 & 1 & 0 & 1 & -- \\
\hline 4 & 1 & 1 & 0 & 1 & -- \\
\hline 5 & 1 & 0 & 1 & 0 & -- \\
\hline 6 & 1 & 1 & 1 & 0 & -- \\
\hline 7 & 1 & 1 & 0 & 1 & -- \\
\hline 8 & 1 & 0 & 1 & 0 & -- \\
\hline 9 & 0 & 1 & 0 & 0 & -- \\
\hline 10 & 1 & 0 & 1 & 0 & -- \\
\hline 11 & 1 & 1 & 1 & 0 & -- \\
\hline 12 & 0 & 1 & 0 & 0 & -- \\
\hline 13 & 1 & 0 & 0 & 1 & -- \\
\hline 14 & 1 & 0 & 0 & 1 & -- \\
\hline 15 & 1 & 0 & 1 & 1 & -- \\
\hline 16 & 1 & 0 & 0 & 1 & -- \\
\hline 17 & 1 & 1 & 0 & 0 & -- \\
\hline 18 & 1 & 0 & 1 & 1 & -- \\
\hline 19 & 1 & 0 & 0 & 1 & -- \\
\hline 20 & 1 & 1 & 0 & 0 & -- \\
\hline 21 & 1 & 1 & 0 & 1 & -- \\
\hline 22 & 0 & 1 & 0 & 0 & -- \\
\hline 23 & 1 & 0 & 1 & 0 & -- \\
\hline No of 1's $\left(t_{j}\right)$ & 19 & 12 & 10 & 10 & 51 \\
\hline No of 0 's $\left(r-t_{j}\right)$ & 4 & 11 & 13 & 13 & 41 \\
\hline Total $r$ & 23 & 23 & 23 & 23 & 92 \\
\hline Proportion of 1 's $\left(p_{j}\right)$ & 0.826 & 0.522 & 0.435 & 0.435 & 0.554 \\
\hline
\end{tabular}

Now using the proportion of 1's or successes of Table 3 in (4), we have

$$
\begin{aligned}
\chi^{2} & =\frac{(23)(0.272)^{2}+(-0.032)^{2}+(-0.119)^{2}+(-0.119)^{2}}{(0.554)(0.446)} \\
& =\frac{(23)(0.074+0.001+0.014+0.014)}{0.247} \\
& =\frac{(23)(0.103)}{0.247}=\frac{2.3695}{0.247}=9.591
\end{aligned}
$$




\section{PAIRWISE COMPARISON IN REPEATED MEASURES}

With $c-1=5-1=4$ degrees of freedom it is statistically significantly at

$\alpha=0.05\left(\chi_{0.95,4}^{2}=9.488\right)$. This means that students' performance seems to differ significantly from year to year. In fact the results of Table 3 suggest that students' success rates declined progressively during the years of study. Further interest may now be in comparing some of the years in terms of success rates achieved to determine which ones may be responsible for the rejection of $H_{o}$. For example, one may wish to compare year 5 with year 2 to determine whether there is any significant difference in the relative success rates for the two years. That is interest may be in testing the null hypothesis of (18) with $\pi_{o} \geq 0$.

Again using the data of Table 3 with $p_{5}=0.435$ and $p_{2}=0.826$ in (26)

$$
\chi^{2}=\frac{(23)(0.435-0.826)^{2}}{(2)(0.554)(0.446)}=\frac{3.516}{0.4942}=7.117
$$

With $c-1=5-1=4$ degrees of freedom it is not statistically significant at $\alpha=0.05$.

Similar comparisons can also be made for other pairs of years. Pairwise comparisons for other years (e.g., year 2 versus year 1, year 3 versus year 2) may be conducted to ascertain whether the relative success rates for these pairs of years are statistically different from zero. Thus for year 3 versus year 2, from Table 3 that $p_{3}=0.522$. From (27) with $\pi_{o}=0$

$$
\chi^{2}=\frac{(23)(0.522)^{2}}{(0.554)(0.446)}=\frac{6.267}{0.247}=25.372
$$

which with 4 degrees of freedom is statistically significant at $\alpha=0.05$. Similarly for year 2 relative to year $1, p_{2}=0.826$,

$$
\chi^{2}=\frac{(23)(0.826)^{2}}{(0.554)(0.446)}=\frac{15.692}{0.247}=63.530
$$

and with 4 degrees of freedom is also statistically significant at $\alpha=0.05$.

These results indicate that students significantly improved their performances during their second and third years of study relative to the immediately preceding years. Note that if it is required that students must achieve some critical minimum 


\section{OYEKA \& NNANATU}

score at the end of the second year relative to the first year, then if $\alpha=0.05$, the required minimum score is from equation (29).

$$
p_{2} \geq \frac{3.841}{23+3.841}=\frac{3.841}{26.841}=0.143, \text { or } 14.3 \text { percent }
$$

which is much less than the average success rate of 82.6 percent achieved in year 2 relative to year 1 . Note also that for year 3 and year 2 ,

$$
\chi^{2}=\frac{23(0.522-0.826)^{2}}{2(0.544)(0.446)}=\frac{2.126}{0.486}=4.384
$$

which with 4 degrees of freedom is not statistically significant at $\alpha=0.05$. This implies that there is no statistical difference between the improvement rates of students at their junior year relative to their sophomore year and the improvement rates at the sophomore year relative to the freshman years. In other words the students may have improved their performances equally well in their third year relative to their second year as in the second relative the first year.

Other values of $q_{j k}$ are similarly calculated and the results are presented in Table 5.

Table 5. Values of $q_{j k}\left(\right.$ Under $\left.H_{0}: \Pi_{o}=0\right)$

\begin{tabular}{c|ccccc}
$\boldsymbol{j}$ & \multicolumn{5}{c}{$\boldsymbol{k}$} \\
\hline $2(0.826)$ & -- & $3(0.522)$ & $4(0.435)$ & $5(0.435)$ & Marginal \\
$3(0.522)$ & 4.302 & -- & -- & -- & 63.530 \\
$4(0.435)$ & 7.117 & 0.352 & -- & -- & 23.372 \\
$5(0.435)$ & 7.117 & 0.352 & -- & -- & 17.619 \\
\hline
\end{tabular}

Note: $j$ = Current Trial Relative Proportions; $k$ = Immediate Past Trial Relative Proportions

All chi-square values in Table 5 which are at least equal to 9.488, the critical chi-square value with 4 degrees of freedom at $\alpha=0.05$ are statistically significant. Therefore, all the years are here responsible for the observed significant difference in the relative success rates of students during their study period.

In order to illustrate the efficiency of this proposed method, Friedman Twoway Analysis Of Variance is applied to the above data. The observations within 


\section{PAIRWISE COMPARISON IN REPEATED MEASURES}

each row $(r)$ or blocks are ranked from the largest to the smallest with the rank of ' 1 ' assigned to the largest value and the rank of ' 2 ' assigned to the next largest value and so on, until the rank $c$ is assigned to the smallest value, where $c$ is the number of treatments. The test statistics for $(r \geq 10, c \geq 4)$ are given by

$$
\chi^{2}=\frac{12}{r c(c+1)} \sum_{i=1}^{c} R_{j}^{2}-3 r(c+1)
$$

Table 6. An illustration of the Friedman Two-way Analysis of Variance by Ranks.

\begin{tabular}{lccccc} 
Student & Year 1 & Year 2 & Year 3 & Year 4 & Year 5 \\
\hline 1 & $2.06(3)$ & $2.05(4)$ & $2.29(2)$ & $2.67(1)$ & $1.00(5)$ \\
2 & $1.38(5)$ & $2.08(3)$ & $2.42(2)$ & $2.76(1)$ & $2.00(4)$ \\
3 & $3.54(4)$ & $3.71(3)$ & $3.88(2)$ & $3.51(5)$ & $5.00(1)$ \\
4 & $1.33(5)$ & $2.17(3)$ & $2.33(1)$ & $1.86(4)$ & $2.22(2)$ \\
5 & $2.02(4)$ & $2.37(2)$ & $2.29(3)$ & $2.60(1)$ & $1.00(5)$ \\
6 & $3.08(4)$ & $3.30(3)$ & $3.36(2)$ & $2.73(1)$ & $1.00(5)$ \\
7 & $1.21(5)$ & $2.30(3)$ & $2.70(1)$ & $2.00(4)$ & $2.44(2)$ \\
8 & $1.35(5)$ & $2.25(2)$ & $2.06(3)$ & $2.43(1)$ & $2.00(4)$ \\
9 & $1.88(4)$ & $1.82(5)$ & $3.64(1)$ & $3.39(2)$ & $2.00(3)$ \\
10 & $2.06(4)$ & $3.14(1)$ & $2.44(3)$ & $3.00(2)$ & $1.00(5)$ \\
11 & $1.85(4)$ & $2.50(3)$ & $2.51(2)$ & $2.80(1)$ & $1.00(5)$ \\
12 & $1.94(1)$ & $1.39(3)$ & $1.83(2)$ & $1.06(4)$ & $1.00(5)$ \\
13 & $2.91(3.5)$ & $3.39(2)$ & $2.91(3.5)$ & $2.13(5)$ & $4.00(1)$ \\
14 & $1.16(5)$ & $2.17(1)$ & $1.57(2)$ & $1.21(4)$ & $1.25(3)$ \\
15 & $1.50(4.5)$ & $1.90(2)$ & $1.50(4.5)$ & $1.79(3)$ & $3.50(1)$ \\
16 & $1.54(3)$ & $2.85(1)$ & $2.73(2)$ & $1.00(5)$ & $1.50(4)$ \\
17 & $1.96(4)$ & $2.21(2)$ & $2.57(1)$ & $2.00(3)$ & $1.00(5)$ \\
18 & $1.24(4)$ & $2.29(1)$ & $1.04(5)$ & $1.74(3)$ & $2.00(2)$ \\
19 & $1.26(3)$ & $2.67(1)$ & $1.20(4)$ & $1.18(5)$ & $1.50(2)$ \\
20 & $1.49(4)$ & $2.21(2)$ & $2.57(1)$ & $1.71(3)$ & $1.00(5)$ \\
21 & $1.55(5)$ & $2.50(1)$ & $1.86(3)$ & $1.21(5)$ & $2.00(2)$ \\
22 & $2.46(3)$ & $2.39(4)$ & $3.56(1)$ & $3.50(2)$ & $1.00(5)$ \\
23 & $1.33(4)$ & $2.16(1)$ & $1.25(5)$ & $2.12(2)$ & $1.43(3)$ \\
Rank Sum $\left(\boldsymbol{R}_{\mathbf{j}}\right)$ & 90 & 53 & 56 & 67 & 79 \\
\hline
\end{tabular}


Now using

$$
\begin{aligned}
\chi^{2} & =\frac{12}{r c(c+1)} \sum_{i=1}^{c} R_{j}^{2}-3 r(c+1) \\
\chi^{2} & =\frac{12}{23(5)(5+1)}\left(90^{2}+53^{2}+56^{2}+67^{2}+79^{2}\right)-3(23)(5+1) \\
\chi^{2} & =\frac{12}{r c(c+1)} \sum_{i=1}^{c} R_{j}^{2}-3 r(c+1) \\
\chi^{2} & =16.76
\end{aligned}
$$

which is also significant at $\alpha=0.05$, because $\chi^{2}>\chi_{1-\alpha ; c-1}^{2}, 16.76>9.488$, and $\chi_{1-\alpha ; c-1}^{2}=\chi_{1-0.05 ; 5-1}^{2}=\chi_{0.95 ; 4}^{2}=9.488$. The results are also significant like the proposed methods.

\section{Conclusion}

The proposed method of pairwise comparisons in repeated measures is suitable when interest is not only on testing whether the null hypothesis of no difference is rejected or accepted, but if the null hypothesis is rejected, which individual subjects or their combinations actually contributed to the rejection of the null hypothesis. It is at least as efficient and powerful as competitors.

\section{References}

Conover, W. J. (1980). Practical Nonparametric Statistic. Second Ed. New York: John Wiley \& Sons, Inc.

Davidian, M \& Giltinan, D. M. (1995). Nonlinear Models for Repeated Measurement Data. Boca Raton, FL: Chapman \& Hall/CRC.

Dean, A. \& Voss, D. (1999). Design and Analysis of Experiments. New York: Springer-Verlag.

Fitzmaurice, G., Davidian, M., Verbeke, G., \& Molenberghs, G., Eds. (2008). Longitudinal Data Analysis. Boca Raton, FL: Chapman \& Hall/CRC.

Friedman, M. (1937). The Use of Ranks to Avoid the Assumption of Normality Implicit in the Analysis of Variance. Journal of the American Statistical Association, 32(200), 675-701. 


\section{PAIRWISE COMPARISON IN REPEATED MEASURES}

Girden, E. R. (1992). ANOVA Repeated Measures. New York: Sage Publications.

Hollander, M. \& Wolfe, D. A. (1979). Non-parametric Statistical Methods, New York: John Wiley \& Sons, Inc.

Jones, B. \& Kenward, M. G. (2003). Design and Analysis of Cross-Over Trials, (2 ${ }^{\text {nd }}$ Ed.). London: Chapman and Hall.

Kempthorne, O. (1979). Sampling Inference, Experimental Inference and Observation Inference. Sankhya, 40, 115-145.

Oyeka, I. C. A. (1996). Introduction to applied Statistical Methods. Enugu, Nigeria: Nobern Allocation Publishing Company.

Oyeka, I. C. A. (1990). A Non-Parametric Method for the Analysis of Repeated Reponses. STATISTICA, 50(1), 83-90.

Oyeka, I. C. A. (1986). Family Planning Among Nigerian Postsecondary Female Students. Studies in Family Planning, 17(3), 146-152.

Page, E. B. (1963). Ordered Hypothesis for Multiple Treatments: A Significant Test for Linear Ranks. Journal of American Statistical Association, 58(301), 216-230.

Pan, J-X. \& Fang, K-T. (2002). Growth Curve models and Statistical diagnostics. Springer Series in Statistics. New York: Springer-Verlag.

Prentice, R. L. (1978). Linear Rank Tests with Right Censored Data. BIOMETRIKA, 65, 167-179.

Sen, P. K. (1968). Robustness of Some Nonparametric Procedures in Linear Models. The Annals of Mathematical Statistics, 39(6), 1913-1922.

Sen, P. K. \& Puri, M. L. (1967). On the Theory of Rank Order Tests for Location in the Multivariate One Sample Problem. The Annals of Mathematical Statistics, 38(4), 1216-1228.

Shanghnessy, J. J. (2006). Research methods in Psychology. New York: McGraw-Hill.

Timm, N. H. (2002). Applied Multivariate Analysis. Springer Texts in Statistics. New York: Springer-Verlag.

Vonesh, E. F. \& Chinchilli, V. G. (1997). Linear and Nonlinear Models for Analysis of Repeated Measurements. London: Chapman and Hall. 